\title{
Active clearance of chest drainage catheters reduces retained blood
}

\author{
Joachim Sirch, MD, ${ }^{\text {a }}$ Miroslaw Ledwon, MD, ${ }^{a}$ Tamas Püski, MD, ${ }^{a}$ Ed M. Boyle, MD, ${ }^{b}$ \\ Steffen Pfeiffer, MD, ${ }^{\mathrm{a}}$ and Theodor Fischlein, $\mathrm{MD}^{\mathrm{a}}$
}

\begin{abstract}
Objective: Chest tubes are used to clear blood from around the heart and lungs after heart surgery, but they can be obstructed by a blood clot, leading to retained blood syndrome (RBS). We sought to examine the frequency of RBS and associated morbidity, and to determine the influence of a preventative active chest tube clearance (ATC) protocol on these outcomes.
\end{abstract}

Methods: A multidisciplinary team developed a simple protocol to institute ATC to preventatively clear chest tubes of clot during the first 24 hours after heart surgery. An extensive educational in-service was performed before universal implementation (phase 1). We retrospectively compared data collected prospectively from 1849 patients before universal implementation (phase 0) with data from 256 patients collected prospectively after universal implementation (phase 2), and then used propensity matching for outcomes assessment.

Results: In propensity-matched patients, $19.9 \%$ of patients had interventions for RBS (phase 0). After the implementation of ATC (phase 2), the percent of patients with interventions for RBS was reduced to $11.3 \%$, representing a $43 \%$ reduction in RBS $(P=.0087)$. These patients had a 33\% reduced incidence of postoperative atrial fibrillation from $30 \%$ (78 out of 256) in phase 0 to $20 \%$ (52 out of 256 ) in phase 2. $(P=.013)$.

Conclusions: ATC is associated with a reduced need for interventions for RBS and postoperative atrial fibrillation. Our findings underscore the importance of maintaining chest tube patency in the early hours after cardiac surgery. (J Thorac Cardiovasc Surg 2016;151:832-38)

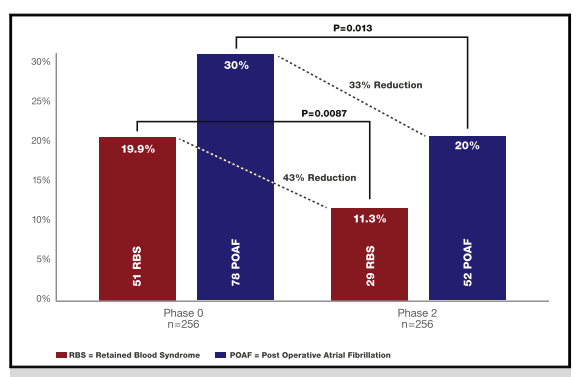

Active tube clearance reduces retained blood syndrome and postoperative atrial fibrillation.

\section{Central Message}

Active tube clearance reduces interventions for retained blood syndrome and postoperative atrial fibrillation, underscoring the importance of maintaining chest tube patency after cardiac surgery.

\section{Perspective}

All patients require chest tubes to drain shed blood after heart surgery, yet clogging of chest tubes is common. We studied a protocol to maintain chest tube patency with active tube clearance and demonstrated an associated reduction in retained blood syndrome and postoperative atrial fibrillation. Our findings underscore the importance of maintaining chest tube patency in outcomes after cardiac surgery.

See Editorial Commentary page 839.
B Supplemental material is available online.

Postoperative bleeding is common to some degree in nearly all patients in the early hours after heart surgery. ${ }^{1}$ To obtain

\footnotetext{
From the a Department of Cardiac Surgery, Kllinikum Nürnberg, Paracelsus Medical University, Nuremberg, Germany; and ${ }^{\mathrm{b}}$ St Charles Medical Center, Bend, Ore.

Read at the Foundation for the Advancement of Cardiothoracic Surgical Care Cardiovascular-Thoracic Critical Care Meeting, Washington, DC, October 10, 2014

Received for publication Nov 20, 2014; revisions received Oct 1, 2015; accepted for publication Oct 10, 2015; available ahead of print Nov 21, 2015.

Address for reprints: Theodor Fischlein, MD, Department of Cardiac Surgery, Klinikum Nürnberg Paracelsus Medical University, Breslauer Str 201, 90471 Nuremberg, Germany (E-mail: theodor.fischlein@klinikum-nuernberg.de). $0022-5223$

Copyright $(92016$ by The American Association for Thoracic Surgery. Published by Elsevier Inc. This is an open access article under the CC BY-NC-ND license (http:// creativecommons.org/licenses/by-nc-nd/4.0/).

http://dx.doi.org/10.1016/j.jtcvs.2015.10.015
}

adequate evacuation, chest tubes are used to drain shed blood and prevent retained collections around the heart and lungs. ${ }^{2}$ Chest tubes can obstruct with clot, impairing their evacuation capacity. Recently, a prospective observational study ${ }^{3}$ quantified that $36 \%$ of chest tubes obstruct after heart surgery, often in the internal portion where the obstruction goes unnoticed by caregivers. We hypothesized that chest tube obstruction might contribute to retained blood syndrome (RBS) after cardiac surgery. To study this hypothesis we initiated a continuous quality improvement process to assess the incidence of RBS, then develop and implement a universal protocol using active tube clearance (ATC) to periodically clear the internal lumen of chest tubes.

\section{MATERIALS AND METHODS}

Data were collected from our institutional cardiac surgery database. Structured data elements are routinely prospectively collected and 

Abbreviations and Acronyms
ATC = active tube clearance
$\mathrm{CABG}=$ coronary artery bypass surgery
$\mathrm{ICU}=$ intensive care unit
NYHA $=$ New York Heart Association
POAF $=$ postoperative atrial fibrillation
RBS $=$ retained blood syndrome
VEGF $=$ vascular endothelial growth factor

available for retrospective analysis. Operative variables included the type of surgery (coronary artery bypass grafting [CABG], valve, CABG + valve, and other) and reoperative status. Procedures in the "other" category included isolated ascending and aortic arch procedures. The primary outcomes measured were interventions for RBS, a composite outcome consisting of any of the following interventions: take back for re-exploration for hemorrhage; pericardial interventions (eg, pericardial window or pericardiocentesis); and pleural interventions for hemothorax, pneumothorax, or effusions. Patients who had interventions for $>1$ component of RBS were only counted once. Patients who had the diagnosis of pleural or pericardial effusion or hemothorax or hemopneumothorax but did not undergo a specific invasive intervention were excluded. Secondary outcomes included postoperative atrial fibrillation (POAF), cardiac arrest, permanent stroke, postoperative hospital length of stay, and the total chest tube drainage volume (in milliliters). All patients were fitted with at least 1 $28 \mathrm{~F}$ chest tube in the anterior mediastinum. We do not routinely open the pleura to harvest the mammary artery, but when it happens, the surgeons place a pleural $28 \mathrm{~F}$ chest tube. Rarely, a retro cardiac $28 \mathrm{~F}$ chest tube is placed. Blake or channel-type drains were not used in any patient in this study. All patients were treated with tranexamic acid. An institutional trigger to transfuse for hemoglobin values of 7.5 to $8 \mathrm{~g} / \mathrm{dL}$ was adhered to in all phases of this study.

From January 1, 2011, to June 11, 2014, 3226 adult cardiac surgical procedures were performed at the Nuremberg Cardiovascular Center. Patients were divided into 4 phases for analysis.

\section{Phase 0: Pre-ATC Protocol}

From January 1, 2011, to December 31, 2012, 1849 cardiac surgery procedures were performed. No patients in this group were treated with ATC. These patients were divided into those with any of the RBS interventions versus those without to establish a baseline for measurement of clinical outcomes.

\section{Phase 1: Limited Implementation for ATC Protocol Development, Training, and Compliance Verification}

A multidisciplinary team developed a simple protocol to institute ATC to clear chest tubes during the first 24 hours after heart surgery. The PleuraFlow Active Clearance Technology System (ClearFlow, Inc, Anaheim, Calif) is a chest tube clearance apparatus with a mechanism to actively keep the entire inner diameter of the chest tube clear of obstructing blood clot or fibrinous debris. ${ }^{4}$ Care providers periodically advance a clearance apparatus back and forth within the catheter by actuating the shuttle that couples via a magnet to the clearance member to maintain sterility while the tube is cleared.

Multidisciplinary team meetings were held for protocol development with cardiac surgical staff, resident physicians and fellows, anesthesiologists and critical care physicians, and cardiac intensive care unit (ICU) nurses. The objective was to develop a simple protocol to implement ATC that could be integrated into the workflow. In prior studies, the most common sites for bleeding identified at reoperation were the mediastinum, sternum, internal thoracic artery bed, and coronary anastomosis sites. ${ }^{5,6}$ For sake of simplicity, it was decided to use a single ATC unit (28F) in an anterior mediastinal position. After 24 hours, the chest tube with ATC was removed, or the chest tube was left in place and the ATC pulled back and its use was discontinued. Most were removed by the second postoperative day. Surgeons were allowed to place additional conventional chest tubes at their discretion; however, in a majority only a single mediastinal ATC was used. The protocol developed allows for more frequent use early on, when chest tube outputs tend to be higher, and less so in subsequent hours, as well as on an as-needed basis (Appendix E1). ${ }^{7}$ The nurses were free to strip and milk the conventional chest tubes as needed. An extensive educational in-service was performed before universal implementation for training of all nurses and physician in the ICU with compliance verification. This protocol was rolled out in phase 1 starting January 1 , 2013, through November 30, 2013, during which time there were 914 heart surgery cases.

\section{Phase 2: Universal Implementation of ATC Protocol}

We implemented phase 2 with ATC universally in all consecutive patients from December 1, 2013, to March 16, 2014.

\section{Phase 3: Postprotocol Remeasurement}

In this phase we stopped the universal implementation of ATC and returned to using all conventional chest tubes (without ATC) and repeated measurement of outcomes (March 18-June 11, 2014).

This study was an investigator-initiated study that was supported in part by a research grant from ClearFlow, Inc. The study site investigators had full access to the data, the ability to analyze them independently from the sponsor, and sole authority to make the final decision regarding publication. ClearFlow, Inc, played no role in the collection of data and had no right to approve or disapprove publication of the finished manuscript.

\section{Measurement and Analysis}

Our institutional ethics committee and an independent ethics committee review board approved this study. We compared results from 1849 patients before (phase 0) with 256 patients after (phase 2) universal implementation, and then the results of stopping the protocol in 222 patients (phase 3 ), to determine the influence of ATC on outcomes. Two hundred fifty-eight patients were approached for consent in phase 2, and 256 agreed to provide consent to participate. A complete set of data was available from all patients except for chest tube drainage $(\mathrm{n}=234)$ and ventilator hours $(\mathrm{n}=255)$ in phase 2 .

Comparisons of categorical variables used a $\chi^{2}$ or Fisher exact test, as appropriate, whereas comparisons of continuous variables used Welch test if the variable was symmetrically distributed and Wilcoxon rank sum test if the variable had a skewed distribution. Propensity scoring was used to balance the distributions of measured potentially confounding baseline covariates using the matchit function from the R package MatchIt (R Foundation for Statistical Computing, Vienna, Austria) with 1:1 nearest neighbor matching based on age, gender, operative status (urgent or elective), redo status, procedure (CABG, valve, $\mathrm{CABG}+$ valve, or other), and use of anticoagulants. The analysis compared matched pairs using McNemar test for categorical variables, paired $t$ tests for symmetrically distributed variables, and Wilcoxon signed-rank test for skewed continuous variables.

\section{RESULTS}

The overall incidence of RBS at baseline (phase 0) was $19.5 \%$ (360 out of 1849 ). The incidence of RBS in phase 0 was not markedly different for surgery types: $18 \%(182$ out of 1011) for patients undergoing CABG-only, 19\% 
(82 out of 436 ) for patients undergoing valve surgery, $21 \%$ (55 out of 260) for patients undergoing combined valve/ CABG, $29 \%$ (41 out of 142 ), $25 \%$ (36 out of 142 ) for patients undergoing other types of surgery. Patients in phase 0 and phase 2 were comparable, except an increased number of patients with $\mathrm{CABG} / \mathrm{valve}$ in phase 0 and slightly higher New York Heart Association (NYHA) class II and III patients in phase 2 (Table E1). In phase 2 there was a $42 \%$ reduction in the primary end point of RBS from $19.5 \%$ (360 out of 1849 ) to $11.3 \%$ (29 out of 256 ) (Table E2).

To account for potential differences between phase 0 and phase 2, a propensity score model was used to match a subcohort of patients in phase 0 who were well balanced for comorbidities and operative variables with patients in phase 2 . After propensity matching, 256 of 1849 patients in phase 0 were selected for comparison with 256 patients in phase 2. Propensity-score matching between phase 0 and 2 found agreement for $97.7 \%$ for gender, $97.3 \%$ for operative status, $80.9 \%$ for procedures, $98.1 \%$ for the use of anticoagulants, $99.2 \%$ for redo status, and $95.7 \%$ for an age difference $<5$ years. After matching, there were no differences between phase 0 and phase 2 with respect to age, sex, preoperative anticoagulation, hematocrit, chronic obstructive pulmonary disease, hypertension, ejection fraction, operative type, elective status, reoperative status, cardiopulmonary bypass time, crossclamp time, or the use of deep hypothermic circulatory arrest (Table 1). There was a slightly higher number of NYHA class III in phase 2 compared with matched patients in phase 0 , although NYHA class I and IV were similar and the ejection fractions were not statistically different between groups.

Following matching, $19.9 \%$ (51 out of 256) had at least 1 intervention for RBS in phase 0 (Table 2). Of matched patients with RBS in phase $0,4.7 \%$ (12 out of 256) underwent re-exploration for bleeding, 2.7\% (7 out of 256) underwent an intervention for pericardial effusion, $11.7 \%$ (30 out of 256) underwent an intervention for pleural effusion (thoracentesis or chest tube drainage), and 3.9\% (10 out of 256) underwent an intervention for pneumothorax (Table 2). After the universal implementation of ATC in phase 2, the percent of matched patients with interventions for ATC was reduced by $43 \%$ to $11.3 \%$ (29 out of 256$)(P=.0087)$. This was primarily due to a reduction in interventions to treat pleural effusions. The incidences of re-exploration for bleeding, interventions for pericardial effusions, and interventions for pneumothorax were lower in phase 2 than in matched patients in phase 0 ; however, individually the differences did not reach statistical significance. Phase 2 patients had a significantly reduced incidence of POAF overall compared with matched patients in phase $0(P=.013)$. There was not a statistically significant reduction in hospital mortality, cardiac arrest, or permanent stroke. Median chest drainage $(P=.0024)$ and
TABLE 1. Matched comparison of demographic characteristics for phase 2 versus phase 0

\begin{tabular}{|c|c|c|c|}
\hline Characteristic & $\begin{array}{c}\text { Phase 0 } \\
(n=256)\end{array}$ & $\begin{array}{c}\text { Phase } 2 \\
(n=256)\end{array}$ & $\begin{array}{c}\text { McNemar or } \\
\text { paired } t \text { test } \\
P \text { value } \\
\end{array}$ \\
\hline Age $(y)$ & $68.6 \pm 10.6$ & $68.1 \pm 10.9$ & .059 \\
\hline Male & $197(77)$ & $199(78)$ & .68 \\
\hline Preoperative anticoagulation & $65(25)$ & $62(24)$ & .37 \\
\hline Clopidogrel & $37(14)$ & $27(11)$ & .22 \\
\hline Warfarin & $15(6)$ & $19(7)$ & .56 \\
\hline Aspirin & $173(68)$ & $174(68)$ & 1 \\
\hline $\begin{array}{l}\text { Preoperative hematocrit } \\
\quad(\mathrm{n}=255)\end{array}$ & $40.0(4.7)$ & $39.7(5.5)$ & .59 \\
\hline $\begin{array}{l}\text { Chronic obstructive } \\
\text { pulmonary disease }\end{array}$ & $37(14)$ & $42(16)$ & 6 \\
\hline Hypertension & $234(91)$ & $241(94)$ & .31 \\
\hline \multicolumn{4}{|l|}{$\begin{array}{l}\text { New York Heart Association } \\
\text { functional class }\end{array}$} \\
\hline I & $24(9)$ & $17(7)$ & .28 \\
\hline II & $62(24)$ & $38(15)$ & .01 \\
\hline III & $148(58)$ & $179(70)$ & .0088 \\
\hline IV & $21(8)$ & $22(9)$ & 1 \\
\hline Ejection fraction $(\mathrm{n}=255)$ & $58.0 \pm 12.8$ & $57.1 \pm 12.4$ & .44 \\
\hline \multicolumn{4}{|l|}{ Operative type } \\
\hline $\begin{array}{l}\text { Coronary artery bypass } \\
\text { grafting }\end{array}$ & $150(59)$ & $148(58)$ & .89 \\
\hline Valve & $60(23)$ & $65(25)$ & .55 \\
\hline $\begin{array}{l}\text { Coronary artery bypass } \\
\text { grafting }+ \text { valve }\end{array}$ & $20(8)$ & $20(8)$ & 1 \\
\hline Other & $26(10)$ & $23(9)$ & .37 \\
\hline Elective status & $181(71)$ & $178(70)$ & .45 \\
\hline Required reoperation & $21(8)$ & $23(9)$ & .48 \\
\hline $\begin{array}{l}\text { Coronary artery bypass } \\
\text { time }(\min )(\mathrm{n}=251)\end{array}$ & $96.3 \pm 56.3$ & $98.1 \pm 49.0$ & .57 \\
\hline $\begin{array}{l}\text { Crossclamp time }(\mathrm{min}) \\
\quad(\mathrm{n}=251)\end{array}$ & $57.5 \pm 32.2$ & $57 \pm 31.5$ & .87 \\
\hline $\begin{array}{l}\text { Deep hypothermic } \\
\text { circulatory arrest }\end{array}$ & $6(2)$ & $3(1)$ & .45 \\
\hline
\end{tabular}

Values are presented as mean \pm standard deviation or $\mathrm{n}(\%)$.

ventilation hours $(P=.0047)$ were reduced in phase 2 compared with matched patients in phase 0 , but not length of stay $(P=.24)$ (Table 3$)$.

The baseline was reassessed for potential temporal trends after the completion of phase 2. Matched patients in phase 3 and phase 0 remained similar in terms of age, gender, preoperative anticoagulation, chronic obstructive pulmonary disease, hypertension, ejection fraction, operative type, elective status, reoperative status, cardiopulmonary bypass time, and crossclamp time (Table 4). There was a slightly higher number of NYHA class III in phase 3 compared with matched patients in phase 0 , although NYHA class I and IV were not statistically different. The mean ejection fraction was slightly lower in phase 3 $(58.3 \% \pm 13.1 \%$ vs $54.9 \% \pm 13.8 \% P=.01)$. Operative 
TABLE 2. Propensity-matched postoperative outcomes in phase 2 versus phase 0

\begin{tabular}{lcccc}
\hline \multicolumn{1}{c}{ Outcome } & $\begin{array}{c}\text { Phase 0 } \\
(\mathbf{n = 2 5 6 )}\end{array}$ & $\begin{array}{c}\text { Phase 2 } \\
(\mathbf{n = 2 5 6 )}\end{array}$ & \% Reduction & $\begin{array}{c}\boldsymbol{P} \\
\text { value }\end{array}$ \\
\hline $\begin{array}{l}\text { Retained blood syndrome } \\
\quad 51(19.9)\end{array}$ & $29(11.3)$ & 43 & .0087 \\
$\quad$ composite) & & & & \\
Re-exploration & $12(4.7)$ & $9(3.5)$ & 26 & .65 \\
Pleural intervention & $30(11.7)$ & $17(6.6)$ & 44 & .061 \\
Pericardial intervention & $7(2.7)$ & $1(0.4)$ & 85 & .077 \\
Pneumothorax & $10(3.9)$ & $7(2.7)$ & 44 & .63 \\
Postoperative atrial & $78(30)$ & $52(20)$ & 33 & .013 \\
$\quad$ & & & & \\
$\quad$ fibrillation & $4(2)$ & $4(2)$ & 0 & 1 \\
Mtroke & $2(5)$ & $12(5)$ & 0 & 1 \\
\hline
\end{tabular}

Values are presented as $\mathrm{n}(\%)$.

characteristics were similar, except a higher number of patients undergoing deep hypothermic circulatory arrest in phase $0(6[3 \%]$ vs $0[0 \%] ; P=.041)$. The RBS rate was comparable in phase $3(17.6 \%)$ versus matched baseline phase 0 patients $(17.6 \%)(P=1)$, as was the POAF rate $(31.5 \%$ in phase 3 vs $23.9 \%$ in matched phase 0 ; $P=.079$ ) (Table 5). A significant reduction in ventilator time persisted from matched phase 0 to matched phase 3 patients (Table 6).

\section{DISCUSSION}

Chest tubes can obstruct, limiting their evacuation capacity. In a survey of cardiothoracic surgeons and cardiac surgery nurses, $100 \%$ had observed chest tube clogging and a large majority recognized adverse events related to this complication. ${ }^{2}$ In a prospective observational study, $36 \%$ of chest tubes were documented as occluded after heart surgery within the first 24 hours. ${ }^{3}$ Current methods to prevent chest tube clogging, such as chest tube stripping and milking, have not been shown to be effective, and may be harmful. 8,9

We set out to define the incidence of RBS at our institution and determine if a protocol to better maintain chest tube patency improves outcomes. We focused specifically on interventions for retained blood rather than more broadly on diagnosis of retained blood because the need for an intervention suggests a more clinically relevant subset of patients than those who simply have a diagnosis of an effusion, for example, but are treated medically. Our incidence of RBS interventions was $20 \%$. Our analysis suggests that the need for interventions for RBS is not predictable preoperatively by the type of procedure performed (CABG, valve, CABG + valve, or other), the urgency status, or if the case was a reoperation. Accordingly, we chose to develop a universal use protocol with the goal of preventing RBS by proactively maintaining chest tube patency in all patients, rather than only selected high-risk patients.

Next we set out to determine if by implementing our universal protocol to keep chest tubes free of blood clot during the early hours after heart surgery we could reduce RBS. We chose to use the PleuraFlow Active Clearance Technology System, a device that allows nurses to periodically clean the entire length of the chest tube by breaking down clots with a loop on a guide wire. ${ }^{4}$ ATC has been shown to be highly effective reducing RBS in preclinical studies. ${ }^{10,11}$ ATC had been assessed in a limited evaluation to be implementable in clinical settings. ${ }^{12}$ The clinical efficacy for ATC in reducing postoperative complications has never been tested.

Using this methodology, we found a substantial reduction in RBS in patients treated with the ATC protocol. In addition, we noted a significant reduction in POAF with the implementation of a universal ATC protocol (Figure 1). The reduction in RBS was primarily from a reduction in pleural and pericardial effusions. We postulate that the mechanism of reduced effusions may in part be related the well-described cross-talk between coagulation and inflammation that may ensue once blood is retained in the pericardial or pleural spaces. ${ }^{13,14}$ Studies have documented that early pleural and pericardial effusions are primarily exudative, bloody, and inflammatory. ${ }^{15-18}$ Blood retained in the pericardial or pleural spaces, even if in insufficient volume to cause mechanical compressive compromise, undergoes inflammatory changes over the subsequent days that can result in exudative fluid production that manifests as pericardial or pleural effusions. ${ }^{19,20}$ As blood clots, thrombin is generated, which amplifies an acute and chronic inflammatory responses within the pericardial and pleural spaces. ${ }^{21}$ In response, inflammatory mediators are locally produced that are known to activate tissue permeability factors by mesothelial cells, such as vascular endothelial growth factor (VEGF). ${ }^{22}$ VEGF is the primary mediator of exudative permeability leading to effusions. ${ }^{22}$ VEGF levels have been shown to rise and stay elevated in effusions after

TABLE 3. Differences between phase 2 and phase 0 for matched pairs

\begin{tabular}{|c|c|c|c|c|c|c|}
\hline Variable & Minimum & 25th percentile & Median & 75th percentile & Maximum & $P$ value \\
\hline Chest tube drainage $(\mathrm{mL})(\mathrm{n}=231)$ & -5750 & -350.0 & -50.0 & 137.5 & 2250 & .0024 \\
\hline Length of stay $(\mathrm{d})(\mathrm{n}=256)$ & -115 & -4 & 0 & 4 & 65 & .24 \\
\hline Ventilator time $(\mathrm{h})(\mathrm{n}=255)$ & -1590 & -9 & -2 & 4.50 & 1141 & .0047 \\
\hline
\end{tabular}


TABLE 4. Matched comparison of demographic characteristics for phase 3 versus phase 0

\begin{tabular}{|c|c|c|c|}
\hline Characteristic & $\begin{array}{c}\text { Phase 0 } \\
(n=222)\end{array}$ & $\begin{array}{c}\text { Phase } 3 \\
(\mathrm{n}=222)\end{array}$ & $\begin{array}{c}\text { McNemar or } \\
\text { paired } t \text { test } \\
P \text { value }\end{array}$ \\
\hline Age (y) & $67.2 \pm 11.7$ & $67.9 \pm 11.0$ & .41 \\
\hline Male & $158(71)$ & $160(72)$ & .91 \\
\hline \multicolumn{4}{|l|}{ Preoperative anticoagulation } \\
\hline Clopidogrel & $36(16)$ & $18(8)$ & .012 \\
\hline Warfarin & $18(8)$ & $14(6)$ & .58 \\
\hline Aspirin & $136(61)$ & $145(65)$ & .37 \\
\hline $\begin{array}{l}\text { Preoperative hematocrit } \\
\quad(\mathrm{n}=219)\end{array}$ & $38.2(5.3)$ & $39.4(5.9)$ & .023 \\
\hline $\begin{array}{l}\text { Chronic obstructive } \\
\text { pulmonary disease }\end{array}$ & $36(16)$ & $28(13)$ & .34 \\
\hline Hypertension & $199(90)$ & $203(91)$ & .6 \\
\hline \multicolumn{4}{|l|}{$\begin{array}{l}\text { New York Heart Association } \\
\text { functional class }\end{array}$} \\
\hline I & $18(8)$ & $10(5)$ & .17 \\
\hline II & $64(29)$ & $20(9)$ & $<.001$ \\
\hline III & $120(54)$ & $173(78)$ & $<.001$ \\
\hline IV & $20(8)$ & $19(9)$ & 1 \\
\hline Ejection fraction $(\mathrm{n}=219)$ & $58.3(13.1)$ & $54.9 \pm 13.8$ & .01 \\
\hline \multicolumn{4}{|l|}{ Operative type } \\
\hline $\begin{array}{l}\text { Coronary artery bypass } \\
\text { grafting }\end{array}$ & $115(52)$ & $112(50)$ & .81 \\
\hline Valve & $56(25)$ & $64(29)$ & .14 \\
\hline $\begin{array}{l}\text { Coronary artery bypass } \\
\text { grafting }+ \text { valve }\end{array}$ & $29(13)$ & $28(13)$ & 1 \\
\hline Other & $22(10)$ & $18(8)$ & .57 \\
\hline Elective status & $158(71)$ & $154(69)$ & .74 \\
\hline Required reoperation & $10(5)$ & $12(5)$ & .72 \\
\hline $\begin{array}{l}\text { Cardiopulmonary bypass } \\
\qquad(\min )(\mathrm{n}=219)\end{array}$ & $95.3 \pm 45.1$ & $96.8 \pm 47.3$ & .69 \\
\hline $\begin{array}{l}\text { Crossclamp time }(\min ) \\
\quad(\mathrm{n}=219)\end{array}$ & $58.2 \pm 30$ & $57.7 \pm 29.7$ & .89 \\
\hline $\begin{array}{l}\text { Deep hypothermic circulatory } \\
\text { arrest }\end{array}$ & $6(3)$ & $0(0)$ & .041 \\
\hline
\end{tabular}

cardiac surgery. ${ }^{23}$ This causes inflammatory, exudative fluid to weep into the pleural and pericardial spaces, resulting in bloody effusions. One mechanism to explain the reduction in clinically significant effusions with ATC is that by more completely evacuating the shed blood around the heart and lungs, less blood is retained, and subsequently less inflammation and VEGF is generated locally. The result may be less inflammation of the mesothelial cells lining the pleura and pericardium to drive exudative fluid production that results in effusions.

This same mechanism might also contribute to the reduction in POAF. Although there may be many factors that contribute to the development of POAF, RBS in the pericardium has been linked with playing a significant role, perhaps by inducing surface cardiac irritation and
TABLE 5. Propensity-matched postoperative outcomes phase 3 versus phase 0

\begin{tabular}{lccc}
\hline \multicolumn{1}{c}{ Outcome } & $\begin{array}{c}\text { Phase 0 } \\
(\mathbf{n = 2 2 2})\end{array}$ & $\begin{array}{c}\text { Phase 3 } \\
(\mathbf{n}=\mathbf{2 2 2})\end{array}$ & $\begin{array}{c}\boldsymbol{P} \\
\text { value }\end{array}$ \\
\hline Retained blood syndrome (composite) & $39(17.6)$ & $39(17.6)$ & 1 \\
Re-exploration & $10(4.5)$ & $6(2.7)$ & .45 \\
Pleural intervention & $25(11.3)$ & $26(11.7)$ & 1 \\
Pericardial intervention & $1(0.5)$ & $3(1.4)$ & .62 \\
Pneumothorax & $5(2.3)$ & $8(3.6)$ & .58 \\
Postoperative atrial fibrillation & $70(31.5)$ & $53(23.9)$ & .079 \\
Stroke & $5(2.3)$ & $2(0.9)$ & .45 \\
Mortality & $12(5.4)$ & $12(5.4)$ & .45 \\
\hline Values are presented as n (\%). & & &
\end{tabular}

Values are presented as $\mathrm{n}(\%)$.

inflammation. ${ }^{24,25}$ Studies ${ }^{3,26}$ have linked both chest tube clogging and retained pericardial blood with POAF. Other studies $^{26,27}$ have demonstrated that shunting blood through pericardial windows to divert the blood to the pleural spaces reduces POAF. One advantage that ATC may have over pericardiotomy is that the blood is not simply shunted to the pleural spaces (where it can contribute to pleural effusions) and there may be less potential for complications such as herniation and longterm adhesions of the lung to the heart through the widely opened posterior pericardium.

There was not an appreciable reduction in the need for re-explorations for hemorrhage with the use of ATC in phase 2 versus phase 0 . Re-explorations for bleeding are primarily for surgical bleeding, but in some cases no bleeding sources are noted and only clot in and around the mediastinum is found. ${ }^{6}$ One would not expect a reduction in re-explorations to manage surgical bleeding sources by simply improving drainage. In theory, improved drainage may allow a patient with a medical source of bleeding to stay stable in the ICU longer, perhaps avoiding tamponade and thus the trigger to return to the operating room for re-exploration while the coagulation defect is corrected. Similarly, the addition of a single ATC in the mediastinum did not reduce the need for interventions for pneumothorax in this study.

As part of this continuous quality initiative, we examined the data for temporal trends over the course of the study. In phase 3 there was a rebound of RBS and POAF after cessation of the ATC protocol employed in phase 2 suggesting a return of the primary end point. There was also a trend toward reduced ventilator time (in hours) and length of stay over the course of this study through the end of phase 3 suggesting other temporal trends not accounted for by ATC. This may be attributed to other quality improvement efforts in the ICU during the study intervals and thus not likely associated with the use of ATC. There also appeared to be a reduction in the mean total blood loss in phase 2 versus 0 . Individual 
TABLE 6. Median differences between phase 3 and phase 0 for matched pairs

\begin{tabular}{|c|c|c|c|c|c|c|}
\hline Variable & Minimum & 25th percentile & Median & 75th percentile & Maximum & $P$ value \\
\hline Chest tube drainage $(\mathrm{mL})(\mathrm{n}=209)$ & -3850 & -270 & -50.0 & 150 & 2090 & .084 \\
\hline Length of stay $(\mathrm{d})(\mathrm{n}=222)$ & -62 & -5 & -1 & 3 & 53 & .074 \\
\hline Ventilator time $(h)(n=219)$ & -1158 & -12 & -3 & 2 & 674 & $<.001$ \\
\hline
\end{tabular}

chest tube outputs were not quantified and thus the clinical significance of this finding is unclear in this study. One can postulate that perhaps by having an open and functioning chest tube on suction while the patient is bleeding, there is less opportunity for blood to pool around the heart and mediastinum and that this may lead to less pericardial thrombolytic effect and therefore less microvascular bleeding. Further studies to better understand the influence of ATC on chest tube outputs are indicated.

We believe this study is important for a number of reasons. Chest tubes are used during every cardiac surgery procedure, with a known failure rate due to clogging that is much higher than previously expected. ${ }^{2,3}$ The finding that nearly $20 \%$ of patients require interventions for RBS suggests this problem is a clinically significant and potentially a modifiable problem. The current approaches to preventing chest tube clogging, such as milking and stripping, have been shown to be ineffective and may be potentially harmful. ${ }^{8,9}$ Makeshift approaches such as opening tubes (after clogging occurs) and suctioning them or using a balloon catheter to remove clots raise safety concerns. $^{28,29}$ Given the lack of suitable methods to routinely prevent chest tube clogging in the ICU, this study is a step toward studying alternatives.

Although the results are encouraging, important limitations need to be considered. This was not a randomized, prospective trial. As such, we did not control for all variables during the study period. There may have been changes in ICU protocols and other variables that limit the ability to draw conclusions about ventilator times, especially in this study. An additional limitation was that this was a retrospective study of prospectively collected database elements, and such databases may contain incomplete information or errors in the manual extraction of data. Furthermore, there were data elements that were not collected this study, particularly with regard to the numbers and locations of conventional chest tubes, reasons, and findings at re-exploration for bleeding, cytology of effusions, and details regarding coagulopathy. These are important considerations for further study. Although the study size was large enough to compare baseline (phase 0 ) to phases 2 and 3 , the sizes of phase 2 and 3 were too small for robust statistical comparison between these

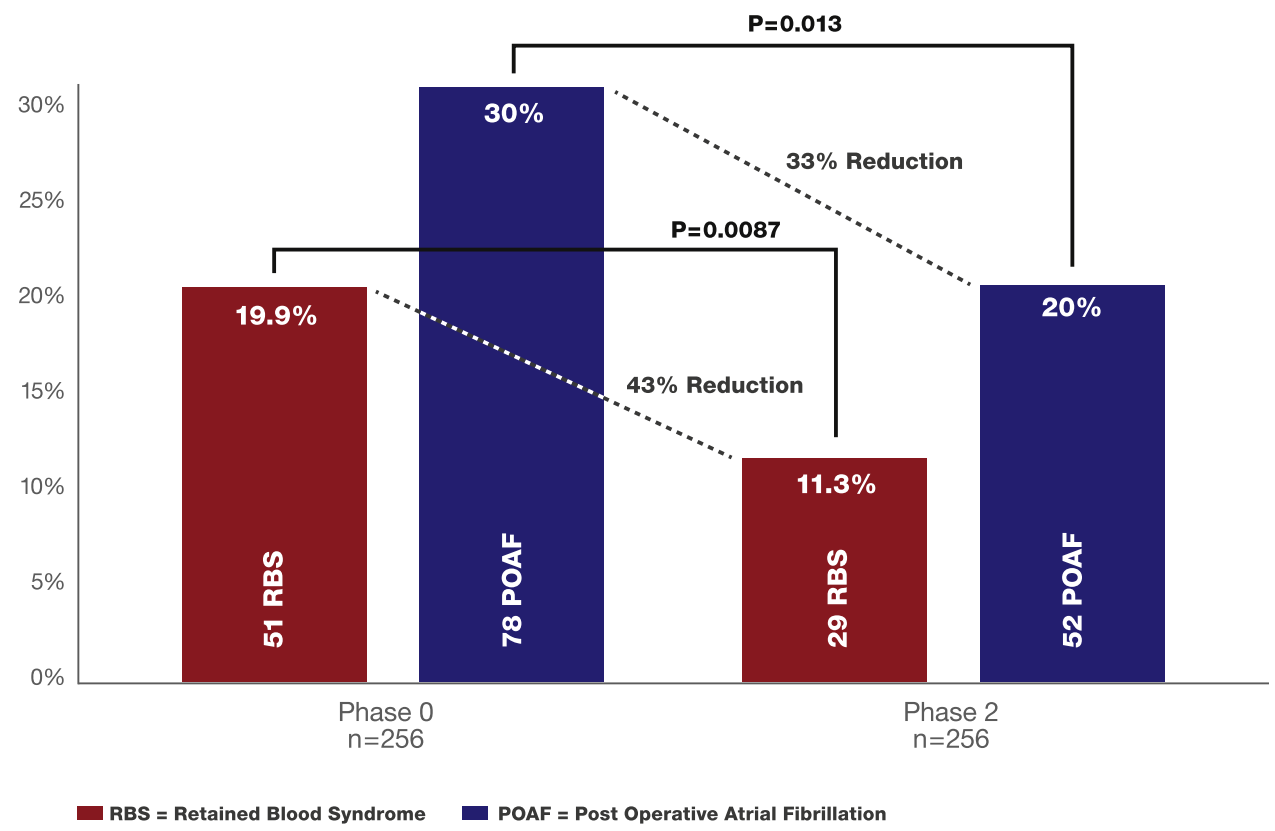

FIGURE 1. Outcomes for matched patients in phase 0 versus phase 2. 
groups. Additionally, we used a proxy to estimate RBS (need for interventions), but did not use direct imaging modalities to quantify the amount of retained blood, which will be considered for further studies. Finally, this analysis did not include the economic data comparing the cost of the technology versus the cost savings from complication avoidance. This is a critical variable in the assessment of any new modality and will be considered in subsequent studies.

\section{CONCLUSIONS}

We observed a signification reduction in the composite end point of RBS as well as interventions for pleural effusions and POAF. These reductions were associated with implementing a formal ATC protocol universally in consecutive patients undergoing heart surgery. Our findings underscore the importance of maintaining chest tube patency during the early recovery period after heart surgery and suggest the need for further studies to devise optimal protocols to optimize chest tube patency.

\section{Conflict of Interest Statement}

Funded in part by a grant from ClearFlow, Inc. Dr Boyle is a founding shareholder and board member of ClearFlow, Inc, and is paid a consulting fee for his work. All other authors have nothing to disclose with regard to commercial support.

The authors thank the nursing staff in the operating room and the ICU physicians and nurses in the cardiothoracic ICUs for their assistance developing and adopting the ATC protocol for this study. The authors also thank Corey Powell, PhD, for providing statistical consultation, and Josef Thalmann.

\section{References}

1. Christensen MC, Dziewior F, Kempel A, von Heymann C. Increased chest tube drainage is independently associated with adverse outcome after cardiac surgery. J Cardiothorac Vasc Anesth. 2012;26:46-51.

2. Shalli S, Saeed D, Fukamachi K, Gillinov AM, Cohn WE, Perrault LP, et al. Chest tube selection in cardiac and thoracic surgery: a survey of chest tube-related complications and their management. J Card Surg. 2009;24:503-9.

3. Karimov JH, Gillinov AM, Schenck L, Cook M, Kosty Sweeney D, Boyle EM, et al. Incidence of chest tube clogging after cardiac surgery: a single-center prospective observational study. Eur J Cardiothorac Surg. 2013;44:1029-36.

4. Shalli S, Boyle EM, Saeed D, Fukamachi K, Cohn WE, Gillinov AM. The active tube clearance system: a novel bedside chest-tube clearance device. Innovat Technol Technique Cardiothorac Vasc Surg. 2010;5:42-7.

5. Loor G, Vivacqua A, Sabik JF III, Li L, Hixson ED, Blackstone EH, et al. Process improvement in cardiac surgery: development and implementation of a reoperation for bleeding checklist. J Thorac Cardiovasc Surg. 2013;146:1028-32.

6. Hall TS, Brevetti GR, Skoultchi AJ, Sines JC, Gregory P, Spotnitz AJ, Re-exploration for hemorrhage following open heart surgery differentiation on the causes of bleeding and the impact on patient outcomes. Ann Thorac Cardiovasc Surg. 2001;7:352-7.

7. Wynne R, Botti M, Copley D, Bailey M. The normative distribution of chest tube drainage volume after coronary artery bypass grafting. Heart Lung. 2007;36:35-42.
8. Day TG, Perring RR, Gofton K. Is manipulation of mediastinal chest drains useful or harmful after cardiac surgery? Interact Cardiovasc Thorac Surg. 2008;7:888-90.

9. Halm MA. To strip or not to strip? Physiological effects of chest tube manipulation. Am J Crit Care. 2007;16:609-12.

10. Arakawa Y, Shiose A, Takaseya T, Fumoto H, Kim HI, Boyle EM, et al. Superior chest drainage with an active tube clearance system: evaluation of a downsized chest tube. Ann Thorac Surg. 2011;91:580-3.

11. Shiose A, Takaseya T, Fumoto H, Arakawa Y, Horai T, Boyle EM, et al. Improved drainage with active chest tube clearance. Interact Cardiovasc Thorac Surg. 2010;10:685-8.

12. Perrault LP, Pellerin M, Carrier M, Cartier R, Bouchard D, Demers P, et al. The PleuraFlow Active Chest Tube Clearance System: initial clinical experience in adult cardiac surgery. Innovat Technol Technique Cardiothorac Vasc Surg. 2012; 7:354-8.

13. Levi M, van der Poll T, Buller HR. Bidirectional relation between inflammation and coagulation. Circulation. 2004;109:2698-704.

14. Farivar AS, Delgado MF, McCourtie AS, Barnes AD, Verrier ED, Mulligan MS. Crosstalk between thrombosis and inflammation in lung reperfusion injury. Ann Thorac Surg. 2006;81:1061-7.

15. Sadikot RT, Rogers JT, Cheng DS, Moyers P, Rodriguez M, Light RW. Pleural fluid characteristics of patients with symptomatic pleural effusion after coronary artery bypass graft surgery. Arch Intern Med. 2000;160:2665-8.

16. Ashikhmina EA, Schaff HV, Sinak LJ, Li Z, Dearani JA, Suri RM, et al. Pericardial effusion after cardiac surgery: risk factors, patient profiles, and contemporary management. Ann Thorac Surg. 2010;89:112-8.

17. Labidi M, Baillot R, Dionne B, Lacasse Y, Maltais F, Boulet LP. Pleural effusions following cardiac surgery: prevalence, risk factors, and clinical features. Chest. 2009; 136:1604-11.

18. Light RW, Rogers JT, Moyers JP, Lee YC, Rodriguez RM, Alford WC Jr, et al. Prevalence and clinical course of pleural effusions at 30 days after coronary artery and cardiac surgery. Am J Respir Crit Care Med. 2002;166:1567-71.

19. Michailova KN. Electron microscopic alterations of the rat's pleura after experimental haemothorax. Ann Anat. 2004;186:115-25.

20. Marchi E, Broaddus VC. Mechanisms of pleural liquid formation in pleural inflammation. Curr Opin Pulm Med. 1997;3:305-9.

21. Chen D, Dorling A. Critical roles for thrombin in acute and chronic inflammation. J Thromb Haemost. 2009;7(Suppl 1):122-6.

22. Grove CS, Lee YC. Vascular endothelial growth factor: the key mediator in pleural effusion formation. Curr Opin Pulm Med. 2002;8:294-301.

23. Chibante AM, Vaz MA, Suso FV. The proliferative cytokines TGF-beta and VEGF in pleural effusions post-coronary artery bypass graft. Rev Port Pneumol. 2006;12:359-67.

24. Tokmaji G, McClure RS, Kaneko T, Aranki SF. Management strategies in cardiac surgery for postoperative atrial fibrillation: contemporary prophylaxis and futuristic anticoagulant possibilities. Cardiol Res Pract. 2013;2013: 637482.

25. Kramer PA, Chacko BK, Ravi S, Johnson MS, Mitchell T, Barnes S, et al. Hemoglobin-associated oxidative stress in the pericardial compartment of postoperative cardiac surgery patients. Lab Invest. 2015;95:132-41.

26. Biancari F, Mahar MA. Meta-analysis of randomized trials on the efficacy of posterior pericardiotomy in preventing atrial fibrillation after coronary artery bypass surgery. J Thorac Cardiovasc Surg. 2010;139:1158-61.

27. Farsak B, Gunaydin S, Tokmakoglu H, Kandemir O, Yorgancioglu C, Zorlutuna Y. Posterior pericardiotomy reduces the incidence of supraventricular arrhythmias and pericardial effusion after coronary artery bypass grafting. Eur J Cardiothorac Surg. 2002;22:278-81.

28. Boyacioglu K, Kalender M, Ozkaynak B, Mert B, Kayalar N, Erentug V. A new use of fogarty catheter: chest tube clearance. Heart Lung Circ. 2015;23: e229-30.

29. Halejian BA, Badach MJ, Trilles F. Maintaining chest tube patency. Surg Gynecol Obstet. 1988;167:521.

Key Words: atrial fibrillation, pericardial effusion, pleural effusions 
APPENDIX E1. ACTIVE TUBE CLEARANCE ACTUATION SCHEDULE

\begin{tabular}{|c|c|c|c|c|}
\hline Location & Phase & Timing & Frequency & Cycles $/ \mathrm{h}$ \\
\hline \multirow[t]{3}{*}{$\begin{array}{l}\text { Operating } \\
\text { room }\end{array}$} & Chest closure & $\begin{array}{l}1 \times \text { at time } \\
\text { of closure }\end{array}$ & & 4 \\
\hline & $\begin{array}{r}\text { Transfer to } \\
\text { intensive }\end{array}$ & $\begin{array}{l}1 \times \text { at transfer } \\
\text { to bed }\end{array}$ & Every $15 \mathrm{~min}$ & \\
\hline & care unit & $\begin{array}{l}\text { Continue use } \\
\text { if delay }\end{array}$ & & \\
\hline \multirow{3}{*}{$\begin{array}{l}\text { Intensive } \\
\text { care unit }\end{array}$} & Early bleeding & $0-8 \mathrm{~h}$ & Every $15 \mathrm{~min}$ & 4 \\
\hline & Slowed bleeding & $8-24 \mathrm{~h}$ & Every $30 \mathrm{~min}$ & 2 \\
\hline & $\begin{array}{l}\text { Serosanguinous } \\
\text { drainage }\end{array}$ & $>24 \mathrm{~h}$ & Every $1 \mathrm{~h}$ & 1 \\
\hline
\end{tabular}

TABLE E1. Unmatched demographic and operative characteristics

\begin{tabular}{|c|c|c|c|c|c|}
\hline Characteristic & $\begin{array}{c}\text { Phase } 0 \\
(n=1849) \\
\end{array}$ & $\begin{array}{c}\text { Phase } 2 \\
(n=256)\end{array}$ & $\begin{array}{c}\text { Phase } 3 \\
(n=222)\end{array}$ & $\begin{array}{l}P \text { value } \\
(0 \text { vs } 2) \\
\end{array}$ & $\begin{array}{l}P \text { value } \\
(0 \text { vs } 3) \\
\end{array}$ \\
\hline Age (y) & $68.7 \pm 10.7$ & $68.1 \pm 10.9$ & $67.9 \pm 11.0$ & .4 & .3 \\
\hline Male & $1327(72)$ & $199(78)$ & $160(72)$ & .05 & .99 \\
\hline \multicolumn{6}{|l|}{ Preoperative anticoagulation } \\
\hline Clopidogrel & $382(21)$ & $27(11)$ & $18(8)$ & $<.001$ & $<.001$ \\
\hline Warfarin & $165(9)$ & $19(7)$ & $14(6)$ & .5 & .24 \\
\hline Aspirin & $1247(67)$ & $174(68)$ & $145(65)$ & .92 & .57 \\
\hline Preoperative hematocrit & $39.4 \pm 4.8$ & $39.7 \pm 5.5$ & $38.1 \pm 5.9$ & .3 & .0038 \\
\hline Chronic obstructive pulmonary disease & $264(14)$ & $42(16)$ & $28(13)$ & .42 & .57 \\
\hline Hypertension & $1680(91)$ & $241(94)$ & $203(91)$ & .10 & .87 \\
\hline \multicolumn{6}{|l|}{ New York Heart Association functional class } \\
\hline I & $139(8)$ & $17(7)$ & $10(5)$ & .70 & .13 \\
\hline II & $469(25)$ & $38(15)$ & $20(9)$ & $<.001$ & $<.001$ \\
\hline III & $1093(59)$ & $179(70)$ & $173(78)$ & $<.001$ & .003 \\
\hline IV & $145(8)$ & $22(9)$ & $19(9)$ & .77 & .81 \\
\hline Ejection fraction & $57.8 \pm 13.5$ & $57.1 \pm 12.4$ & $54.9 \pm 13.8$ & .44 & $<.001$ \\
\hline \multicolumn{6}{|l|}{ Operative type } \\
\hline Coronary artery bypass grafting & $1011(54.7)$ & $148(57.8)$ & $112(50.5)$ & .38 & .26 \\
\hline Valve & $436(23.6)$ & $65(25.4)$ & $64(28.8)$ & .58 & .10 \\
\hline Coronary artery bypass grafting + valve & $260(14.1)$ & $20(7.8)$ & $28(12.6)$ & .0078 & .63 \\
\hline Other & $142(7.7)$ & $23(9.0)$ & $18(8.1)$ & .55 & .93 \\
\hline Elective status & $1246(67)$ & $178(70)$ & $154(69)$ & .54 & .60 \\
\hline Required reoperation & $142(8)$ & $23(9)$ & $12(5)$ & .55 & .28 \\
\hline Cardiopulmonary bypass time (min) & $97.2 \pm 71.1$ & $98.1 \pm 49.0$ & $96.8 \pm 47.3$ & .80 & .90 \\
\hline Crossclamp time (min) & $57.8 \pm 30.5$ & $57.0 \pm 31.5$ & $57.7 \pm 29.7$ & .69 & .96 \\
\hline Deep hypothermic circulatory arrest & $31(2)$ & $3(1)$ & $0(0)$ & .79 & .07 \\
\hline
\end{tabular}

Values are presented as mean \pm standard deviation or $\mathrm{n}(\%)$. 
TABLE E2. Retained blood syndrome (RBS) components (unmatched)

\begin{tabular}{|c|c|c|c|c|c|}
\hline Component & $\begin{array}{c}\text { Phase 0 } \\
(n=1849)\end{array}$ & $\begin{array}{c}\text { Phase } 2 \\
(n=256)\end{array}$ & $\begin{array}{c}\text { Phase } 3 \\
(n=222)\end{array}$ & $\begin{array}{l}P \text { value } \\
(0 \text { vs } 2)\end{array}$ & $\begin{array}{l}P \text { value } \\
(0 \text { vs } 3) \\
\end{array}$ \\
\hline RBS (composite) & $360(20)$ & $29(11)$ & $39(18)$ & .0022 & .56 \\
\hline Re-exploration & $66(3.6)$ & $9(3.5)$ & $6(2.7)$ & 1 & .70 \\
\hline Pleural interventions & $232(12.5)$ & $17(6.6)$ & $26(11.7)$ & .0083 & .80 \\
\hline Pericardial interventions & $35(1.9)$ & $1(0.4)$ & $3(1.4)$ & .12 & .79 \\
\hline Pneumothorax (drainage) & $60(3.2)$ & $7(2.7)$ & $8(3.6)$ & .85 & .93 \\
\hline
\end{tabular}

Values are presented as $\mathrm{n}(\%) . R B S$, Retained blood syndrome. 